\title{
Kinematic Characteristics of National and College Level Weightlifters during the Snatch Technique Using Wearable Inertial Sensors ${ }^{\dagger}$
}

\author{
Munkhbat Tumurbaatar ${ }^{1}$, Batbayar Khuyagbaatar ${ }^{1, * \mathbb{D}}$, Yoon Hyuk Kim ${ }^{2}$ and Ganbat Danaa ${ }^{1}$ \\ 1 Biomechanical Research Laboratory, Department of Technical Mechanics, Mongolian University of Science \\ and Technology, Ulaanbaatar 14191, Mongolia; munkhbat99@yahoo.com (M.T.); \\ ganbatda@must.edu.mn (G.D.) \\ 2 Department of Mechanical Engineering, Kyung Hee University, Seoul 17104, Korea; yoonhkim@khu.ac.kr \\ * Correspondence: batbayarkh@must.edu.mn; Tel.: +976-86075099 \\ + Presented at 8th International Electronic Conference on Sensors and Applications, 1-15 November 2021; \\ Available online: https:/ / ecsa-8.sciforum.net.
}

check for updates

Citation: Tumurbaatar, M.; Khuyagbaatar, B.; Kim, Y.H.; Danaa, G. Kinematic Characteristics of National and College Level Weightlifters during the Snatch Technique Using Wearable Inertial Sensors. Eng. Proc. 2021, 10, 22. https://doi.org/10.3390/ ecsa-8-11255

Academic Editor: Stefano Mariani

Published: 1 November 2021

Publisher's Note: MDPI stays neutral with regard to jurisdictional claims in published maps and institutional affiliations.

Copyright: (C) 2021 by the authors. Licensee MDPI, Basel, Switzerland. This article is an open access article distributed under the terms and conditions of the Creative Commons Attribution (CC BY) license (https:/ / creativecommons.org/licenses/by/ $4.0 /)$.
Abstract: Weightlifting performance is strongly dependent on technique, explosive strength, and flexibility. There are two major lifts involved in competition: the snatch and the clean and jerk, and the snatch is the most technical component of the weightlifting competition. Most technical analyses have previously been performed using either video analysis or conventional optical camera systems. However, few studies have investigated the kinematic characteristics of the weightlifters using inertial measurement unit (IMU) sensors. In this study, we investigated the joint kinematics of the trunk, shoulder, elbow, hip, and knee as well as the main phases during the snatch technique for national and college level weightlifters using multiple IMU sensors. Seven female Mongolian weightlifters (three national level and four college level) participated. Each participant performed three snatch attempts at $70 \%$ of their one-repetition maximum. The joint angles were calculated using three-axis acceleration and three-axis gyroscope data from the IMU sensors. The six main phases of the snatch technique were defined based on knee flexion. All parameters were compared between the national and college level weightlifters. The national team showed a higher elbow range of motion and a greater extension of the hip and knee joints at the second pull compared with college-level athletes. In addition, the college team did not exhibit the transition phase, and the proportion of the turnover phase was larger. This study provides a kinematic difference between the two different level weightlifters, which may help coaches and athletes to improve their training strategy and weightlifting performance.

Keywords: weightlifting; snatch; kinematics; inertial sensors

\section{Introduction}

Weightlifting is a sporting event that requires high technique, explosive strength, and flexibility [1]. There are two major lifts involved in competition: the snatch and the clean and jerk, and the snatch is the most technical component of weightlifting competition that involves both upper and lower extremity movement to lift a maximal weight [2].

Most studies have focused on the difference between different weight categories, barbell weight, and genders. Campos et al. [3] studied the kinematic differences of the snatch technique between different categories. Gourgoulis et al. [1] compared the kinematics of the snatch technique between the male and female weightlifters. Harbili et al. [4] investigated the relationship between the barbell mass and power output during the lifts. Differences in the snatch performances of elite female weightlifters were reported in [5]. However, few studies have focused on the differences between different skill level weightlifters. It was hypothesized that lifters would exhibit similar joint angle profiles and different phases for different skilled lifters. 


\section{Materials and Methods}

In this study, seven female Mongolian weightlifters (three national-level (NL) and four college-level (CL)) participated (Table 1). The trunk, shoulder, elbow, hip, and knee motion data were recorded using the inertial measurement unit (IMU) sensors, which were attached to the chest, waist, arm, forearm, thigh, and shank using the straps (Wearnotch, Notch Interface Inc.). The placement of the sensors was adjusted without interfering with the lifter's performance. Before the experiment, each participant was asked to perform several times of lifts as a warm-up at $50 \%$ of the repetition maximum (RM).

Then, each participant performed three snatch lifts at 70\% of the RM for each athlete under supervision by the coach. The extension angles of the trunk, shoulder, elbow, hip, and knee were calculated from the sensor's raw data using the Madgwick filtering algorithm developed in MATLAB $^{\circledR}$ [6,7] (Figure 1). In our previous study [7], the accuracy of the IMU sensors was compared against the optical motion capture system. The results showed that the joint angles were strongly correlated between the IMU sensors and optical motion capture system with $\leq 5.8 \%$ and correlation of $\mathrm{r} \leq 0.99$.

Table 1. The characteristics of female weightlifters.

\begin{tabular}{cccccc}
\hline Subjects & & $\begin{array}{c}\text { Weight } \\
\text { Category } \mathbf{( k g )}\end{array}$ & Age (Year) & Height (cm) & $\begin{array}{c}\text { Body Weight } \\
\text { (kg) }\end{array}$ \\
\hline \multirow{2}{*}{ National-level } & 1 & 55 & 21 & 150 & 52 \\
$(\mathrm{NL})$ & 2 & 76 & 22 & 162 & 82 \\
& 3 & 87 & 21 & 163 & 87 \\
\hline & 4 & 71 & 18 & 151 & 72 \\
College-level & 5 & 55 & 18 & 152 & 55 \\
(CL) & 6 & 71 & 17 & 155 & 70 \\
& 7 & 64 & 18 & 158 & 64 \\
\hline
\end{tabular}

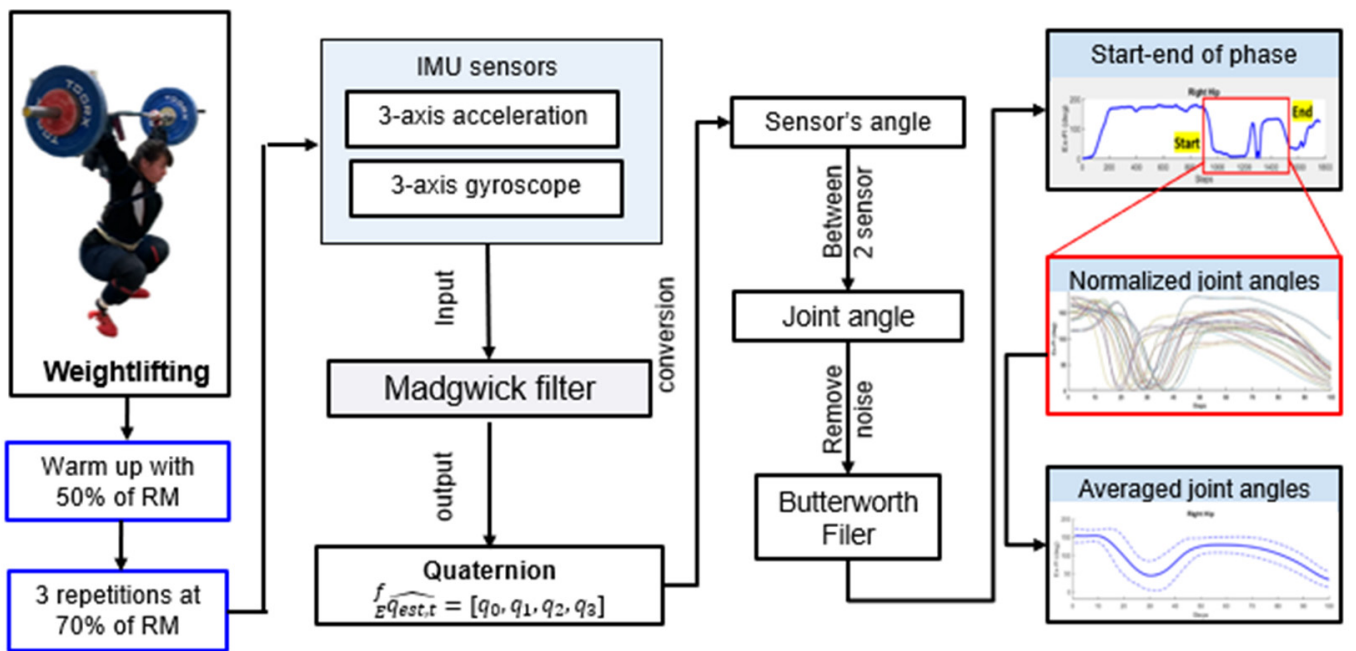

Figure 1. The experiment protocol and data processing.

After calculating the joint angles, the six main phases of the snatch were defined based on knee angle according to the previous study [1]. A snatch lift includes the first pull, transition, second pull, turnover, catch, and recovery phases. For each lift, joint angle data were normalized and divided into 100 steps. Then, each participant's data were averaged for the NL and CL groups, respectively. Then, we compared the joint angles for these two groups. 


\section{Results}

The maximum shoulder, elbow, trunk, hip, and knee extension angles for NL/CL weightlifters were $167 \pm 8^{\circ} / 165 \pm 17^{\circ}, 190 \pm 15^{\circ} / 186 \pm 32^{\circ}, 166 \pm 15^{\circ} / 160 \pm 11^{\circ}$, $164 \pm 12^{\circ} / 136 \pm 11^{\circ}$, and $143 \pm 14^{\circ} / 134 \pm 13^{\circ}$, respectively (Figure 2). The proportion of the phases were different between the two groups (Figure 3). The CL group did not exhibit the transition phase and showed a $7 \%$ longer turnover and $12 \%$ longer catch phase compared to the NL group (Figure 3).
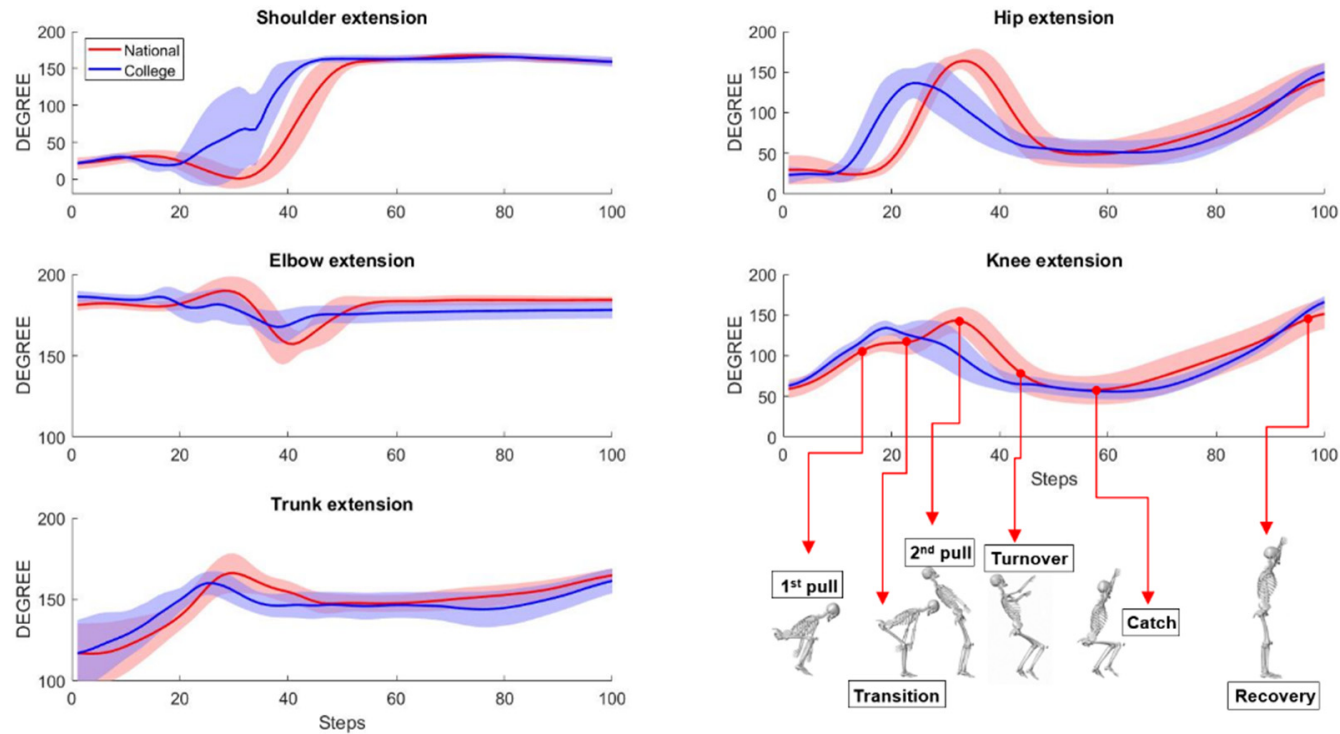

Figure 2. Joint angles for two groups.

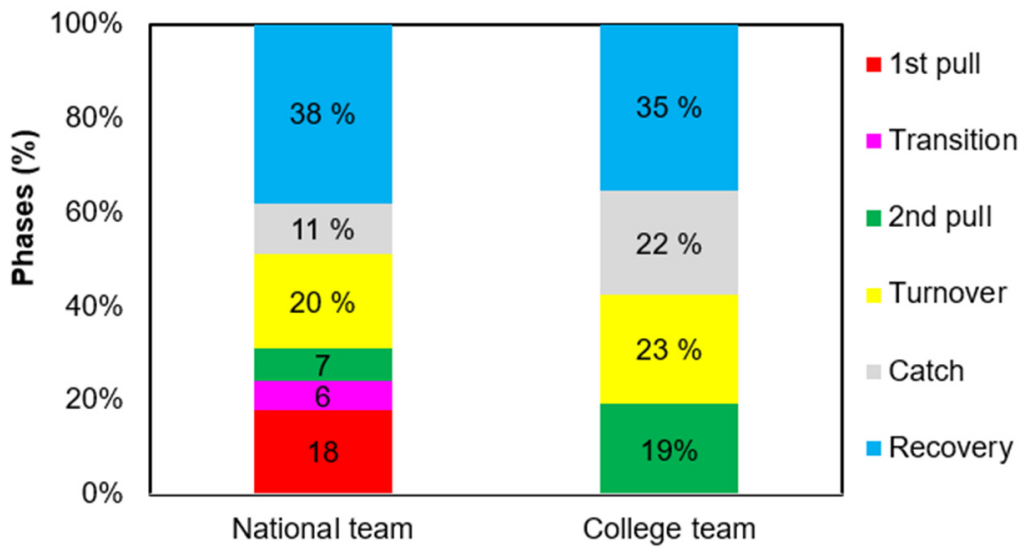

Figure 3. Phase comparison between two groups.

\section{Discussion and Conclusions}

This study compared the joint angles and snatch phases between two groups. The NL groups had a greater extension of the knee and hip at the second pull as well as a higher range of motion of the elbow during the turnover compared with the CL. The phase analysis revealed that the CL group did not exhibit a transition phase since no knee flexion occurred during the pulling, and the turnover and catch phases were also longer in the CL compared with the NL group, which indicates a non-effective technique. This was similar to previous studies where they reported that knee flexion during the transition phase and the faster and deeper drop under the barbell during the turnover and catch phases are crucial during the lifting performance [1,2]. 
Our study has several limitations. The major limitation is that a limited number of individuals have participated, and thus the utilization of statistical methods for quantitative data analysis is powerless. Moreover, a small error in the sensor's data can lead to an increased drift error. The drift error may be more severe in repetitive or cyclic movement [8]. To eliminate this error, we performed each lift separately during the experiment. Finally, the lift variation can be caused by the different weight categories who participated in this study. However, the technique of each participant is unique to the individuals. Therefore, we aimed to find the difference between different skill level weightlifters. Future studies will consider the consistency in the lifts.

In conclusion, we investigated the trunk, shoulder, elbow, hip, and knee joint movements and phases between two different skill level female weightlifters. The wearable sensors allowed for the conduction of weightlifting experiments in the training facilities without interfering with the lifter's performance. The results from the current study may help coaches and athletes to develop a training strategy to improve snatch performance.

Author Contributions: All authors (M.T., B.K., Y.H.K. and G.D.) contributed to the manuscript. For further details, please contact the corresponding author. All authors have read and agreed to the published version of the manuscript.

Funding: This work was supported by the "Mongolia-Japan Engineering Education Development" (MJEED) Project financed by the Japan International Cooperation Agency and executed by the Ministry of Education and Science of Mongolia (Contract NoJ24C16).

Institutional Review Board Statement: The study was conducted according to the guidelines of the Declaration of Helsinki, and approved by the Institutional Review Board of Mongolian University of Science and Technology (IRB\# 020) in 2021.

Informed Consent Statement: Informed consent was obtained from all subjects involved in the study.

Acknowledgments: The authors would like to thank Khosbayar Tsenkherjaw and the participants for their support and collaboration, which made this study possible.

Conflicts of Interest: The authors declare no conflict of interest.

\section{References}

1. Gourgoulis, V.; Aggeloussis, N.; Antoniou, P.; Christoforidis, C.; Mavromatis, G.; Garas, A. Comparative 3-dimensional kinematic analysis of the snatch technique in elite male and female greek weightlifters. J. Strength Cond. Res. 2002, 16, 359-366. [CrossRef] [PubMed]

2. Ho, L.K.W.; Lorenzen, C.; Wilson, C.J.; Saunders, J.E.; Williams, M.D. Reviewing Current Knowledge in Snatch Performance and Technique. J. Strength Cond. Res. 2014, 28, 574-586. [CrossRef]

3. Campos, J.; Poletaev, P.; Cuesta, A.; Pablos, C.; Carratalá, V. Kinematical analysis of the snatch in elite male junior weightlifters of different weight categories. J. Strength Cond. Res. 2006, 20, 843-850. [CrossRef] [PubMed]

4. Harbili, E.; Alptekin, A. Comparative kinematic analysis of the snatch lifts in elite male adolescent weightlifters. J. Sport. Sci. Med. 2014, 13, 417-422.

5. AkkuS, H. Kinematic Analysis of the Snatch Lift with Elite Female Weightlifters During the 2010 World Weightlifting Championship. J. Strength Cond. Res. 2012, 26, 897-905. [CrossRef] [PubMed]

6. Madgwick, S. An Efficient Orientation Filter for Inertial and Inertial/Magnetic Sensor Arrays; University of Bristol: Bristol, UK, 2010.

7. Choi, Y.C.; Khuyagbaatar, B.; Cheon, M.; Batbayar, T.; Lee, S.; Kim, Y.H. Kinematic Comparison of Double Poling Techniques Between National and College Level Cross-Country Skiers Using Wearable Inertial Measurement Unit Sensors. Int. J. Precis. Eng. Manuf. 2021, 22, 1105-1112. [CrossRef]

8. Purevsuren, T.; Khuyagbaatar, B.; Kim, K.; Kim, Y.H. Investigation of knee joint forces and moments during short-track speed skating using wearable motion analysis system. Int. J. Precis. Eng. Manuf. 2018, 19, 1055-1060. [CrossRef] 